\title{
Gaoshan Chinese
}

National Cancer Institute

\section{Source}

National Cancer Institute. Gaoshan Chinese. NCI Thesaurus. Code C158211.

A Chinese person from the Gaoshan ethnic group. 